\title{
Risk of major congenital malformations in relation to maternal overweight and obesity severity: cohort study of 1.2 million singletons
}

\author{
Martina Persson,, ${ }^{1,2}$ Sven Cnattingius, ${ }^{1}$ Eduardo Villamor,, ${ }^{1,3}$ Jonas Söderling, ${ }^{1}$ Björn Pasternak, 1,4 \\ Olof Stephansson, ${ }^{1,5}$ Martin Neovius ${ }^{1}$
}

1Department of Medicine,

Solna, Clinical Epidemiology

Unit, Karolinska Institutet,

SE-171 76 Stockholm, Sweden

${ }^{2}$ Department of Diabetes and

Endocrinology, Sachsska

Children's Hospital,

Södersjukhuset, Stockholm,

Sweden

${ }^{3}$ Department of Epidemiology,

School of Public Health and

Center for Human Growth and

Development, University of

Michigan, Ann Arbor, MI, USA

${ }^{4}$ Department of Epidemiology

Research, Statens Serum

Institut, Copenhagen, Denmark

5Division of Obstetrics and

Gynecology, Department of

Women's and Children's Health,

Karolinska Institutet, Stockholm,

Sweden

Correspondence to: M Persson

Martina.Persson@ki.se

Additional material is published

online only. To view please visit

the journal online.

Cite this as: BMJ 2017;357:j2563 http://dx.doi.org/10.1136/bmj.j2563

Accepted: 24 May 2017

\section{ABSTRACT}

OBJECTIVE

To estimate the risks of major congenital malformations in the offspring of mothers who are underweight (body mass index (BMI) $<18.5$ ), overweight (BMI 25 to $<30$ ), or in obesity classes I (BMI 30 to $<35)$, II $(35$ to $<40)$, or III $(\geq 40)$ compared with offspring of normal weight mothers (BMI 18.5 to $<25$ ) in early pregnancy.

\section{DESIGN}

Population based cohort study.

SETTING

Nationwide Swedish registries.

PARTICIPANTS

1243957 liveborn singleton infants from 2001 to 2014

in Sweden. Data on maternal and pregnancy

characteristics were obtained by individual record linkages.

\section{EXPOSURE}

Maternal BMI at the first prenatal visit.

\section{MAIN OUTCOME MEASURES}

Offspring with any major congenital malformation, and subgroups of organ specific malformations diagnosed during the first year of life. Risk ratios were estimated using generalised linear models adjusted for maternal factors, sex of offspring, and birth year.

RESULTS

A total of 43550 (3.5\%) offspring had any major congenital malformation, and the most common subgroup was for congenital heart defects $(n=20074 ; 1.6 \%)$. Compared with offspring of normal weight mothers (risk of malformations $3.4 \%$ ), the proportions and adjusted risk ratios of any major congenital malformation among the offspring of mothers with higher BMI were: overweight, $3.5 \%$ and 1.05 (95\% confidence interval 1.02 to 1.07 ); obesity class I, $3.8 \%$ and 1.12 (1.08 to 1.15 ), obesity class II, $4.2 \%$ and 1.23 (1.17 to 1.30 ), and obesity class III, $4.7 \%$ and 1.37 (1.26 to 1.49 ). The risks of congenital heart defects, malformations

\section{WHAT IS ALREADY KNOWN ON THIS TOPIC}

Maternal obesity increases risks of congenital malformations

It is not known if risks are increased in offspring of overweight mothers and if risks increase with increasing severity of obesity

\section{WHAT THIS STUDY ADDS}

Risks of major congenital malformations in offspring progressively increase with maternal overweight and severity of obesity of the nervous system, and limb defects also progressively increased with BMI from overweight to obesity class III. The largest organ specific relative risks related to maternal overweight and increasing obesity were observed for malformations of the nervous system. Malformations of the genital and digestive systems were also increased in offspring of obese mothers.

\section{CONCLUSIONS}

Risks of any major congenital malformation and several subgroups of organ specific malformations progressively increased with maternal overweight and increasing severity of obesity. For women who are planning pregnancy, efforts should be encouraged to reduce adiposity in those with a $\mathrm{BMI}$ above the normal range.

\section{Introduction}

Obesity has reached epidemic proportions globally and is now a major health concern in pregnancy, in both high and low income countries. ${ }^{1}$ In particular the prevalence of severe obesity, commonly defined as obesity classes II and III (body mass index (BMI) $\geq 35$ ) is rapidly increasing. ${ }^{2-4}$ In the US, approximately half of the women are overweight or obese at the first antenatal visit, ${ }^{5}$ and the high prevalence of obesity class III (BMI $\geq 40 ; 10-12 \%$ ) in women of reproductive age is of concern. ${ }^{6}$ In Sweden, the prevalence of early pregnancy obesity (BMI $\geq 30$ ) increased from $6.0 \%$ to $12.9 \%$ from 1992 to $2014 .^{7}$ Globally, it was recently reported that the number of women aged 18 years and older with a BMI $\geq 35$ doubled from approximately 50 million to 100 million between 2000 and $2010 .^{8}$

Obesity in pregnancy adversely influences both fetal and neonatal outcomes, ${ }^{9-15}$ including increased risks of major congenital malformations, which are a common cause of stillbirth ${ }^{16}$ and a major cause of infant mortality and long term morbidity. ${ }^{14} 17$ A meta-analysis reported that the offspring of obese mothers are at increased risk of a wide range of congenital malformations, including neural tube defects, cardiovascular anomalies, cleft lip and palate, anorectal atresia, and limb reduction anomalies. ${ }^{18}$ However, associations between increasing severity of obesity and risks of malformations were not analysed and it is not clear if risks are also increased in the offspring of overweight mothers. Several of the included studies also used non-standard definitions of normal weight, overweight, and obesity. ${ }^{19-24}$ Since the prevalence of severe obesity is increasing among women of reproductive age, it is of 
interest to investigate whether risks of major congenital malformations increase with severity of obesity in mothers.

In this study we included information on 1243957 live singleton births in Sweden recorded in the medical birth register between 2001 and 2014. We investigated associations between maternal BMI in early pregnancy and risks of any major congenital malformation as well as risks of the most prevalent subgroups of organ specific malformations.

\section{Methods}

Setting

The study was performed in Sweden, where prenatal and delivery care is publicly funded, and participation in the standardised prenatal care programme is almost $100 \%$. The Swedish medical birth register includes information on close to $100 \%$ of all births in Sweden since 1973. Using standardised prenatal, obstetrical, and neonatal records, information is prospectively collected during pregnancy, delivery, and the neonatal period. ${ }^{25}$ Individual information on maternal height and weight has been included since 1992.

\section{Data sources}

By using the unique personal identification number assigned to each Swedish resident, ${ }^{26}$ we linked data from the medical birth register to the national patient register, ${ }^{27}$ cause of death register, education register, and total population register. ${ }^{28}$ The national patient register includes diagnoses and dates on visits for hospital based inpatient and outpatient care. Diagnoses are coded according to the Swedish version of the ICD10 (international classification of diseases, 10th revision). In Sweden, all pregnant women are offered an ultrasound examination at around 18 weeks of gestation. Abortion after 18 until 22 completed weeks must be approved by the National Board of Health and Welfare. Severe birth defects as indication for late abortion are generally approved. In 2015, the rate of abortions in Sweden was 20.9/1000 women (aged $15-44$ years; $93 \%$ of abortions were performed before 12 weeks of gestation and $83 \%$ before nine weeks of gestation).

\section{Study population}

From 1 January 2001 to 31 December 2014, we retrieved information on 1480892 deliveries recorded in the Swedish medical birth register. We excluded 42638 $(2.9 \%)$ multiple births (since they differ from single births for malformation outcomes ${ }^{29}$ ) and 4598 (0.3\%) stillbirths (where diagnosis and registration of malformations is poor or missing). Of the remaining 1433656 live singleton births, 19863 (1.4\%) were excluded owing to lack of valid personal identification numbers (18929 for the mother and 934 for the infant), as these births could not be linked to other registries. Because we assumed that adiposity is unlikely to cause malformations for which another cause is known, we also excluded 7514 (0.5\%) infants with chromosomal aber- rations, genetic syndromes, malformation syndromes with known causes, and viral infections having a possible association with malformations (see supplementary eMethods). ${ }^{30}$ Finally, seven infants did not have data on sex and were therefore excluded. After these exclusions, 1406272 singletons remained, of whom $1243957(88.5 \%)$ had complete data on all covariates.

Women missing data on BMI were more likely to have missing data on smoking status and family situation (see supplementary eTable 1). Maternal age, level of education, parity, and proportion of women of Nordic origin were similar in women with missing BMI data compared with normal weight women. However, women missing BMI data were more likely to have high education and to be primiparous compared with obese women.

\section{Patient involvement}

No patients were involved in setting the research question or the outcome measures, nor were they involved in developing plans for design, or implementation of the study. No patients were asked to advise on interpretation or writing up of results. There are no plans to disseminate the results of the research to study participants or the relevant patient community.

\section{Main exposure}

We calculated early maternal pregnancy BMI from measured weight and self reported height at the first prenatal visit, which takes place during the first trimester (first 14 weeks of gestation) for $90 \%$ of all women. ${ }^{12}$ We calculated the median height of each mother using information from all available pregnancies. ${ }^{31}$ Data on maternal height and/or weight were missing in $9.6 \%$ of live singleton births (see supplementary eTable 1). Based on BMI, we categorised the women as underweight (BMI $<18.5$ ), of normal weight (18.5 to $<25)$, overweight $(25$ to $<30)$, or in obesity class I (30 to $<35)$, obesity class II $(35$ to $<40)$, or obesity class III $(\geq 40) \cdot{ }^{32}$

\section{Covariates}

Data on parity, whether the mother cohabited with a partner or not, and self reported smoking were registered at the first prenatal visit. Information on maternal age was obtained at delivery, highest attained education was retrieved from the education register, and mother's country of birth was retrieved from the total population register.

\section{Outcomes}

The main outcome was presence of any major congenital malformations in liveborn infants (from 22 completed gestational weeks), as recorded in either the medical birth register, the national patient register within one year of birth (including inpatient and hospital based outpatient care), or the cause of death register. Major congenital malformations were coded according to the ICD-10 classification and were defined according to the European Surveillance of Congenital 
Anomalies classification (EUROCAT; www.eurocat-network.eu; see supplementary eTables 2 and 3 for ICD-10 codes).

We analysed the most common subgroups of major congenital malformations with a prevalence of $\geq 0.1 \%$ as additional outcomes. These included major congenital malformations of the heart, limbs, genital organs, urinary system, digestive system, orofacial clefts, eye, nervous system, and other malformations. In keeping with the EUROCAT definition, patent ductus arteriosus in preterm infants and persistent pulmonary stenosis were not considered as major congenital malformations. Other minor malformations were also excluded in accordance with the EUROCAT classification.

\section{Statistical analysis}

Using generalised linear models with a robust sandwich estimator, we estimated risk ratios and 95\% confidence intervals for the outcomes in offspring of underweight mothers (BMI <18.5), overweight mothers $(25$ to $<30)$, and mothers in obesity classes I (30 to $<35$ ), II ( 35 to $<40)$, and III $(\geq 40)$ compared with the offspring of normal weight mothers (18.5 to $<25)$. To adjust for the possible dependence in outcome introduced by repeated births in the same mother, we constructed models with mother's identification number as a cluster. The outcome was assumed to follow a Poisson distribution. We made adjustments for maternal age, height, parity, early pregnancy smoking status ( $0,1-9$, or $\geq 10$ cigarettes daily), educational level, mother's country of birth, family situation (living or not living with a partner), and sex of offspring.

Subgroup analyses-sex specific subgroup analyses were performed for any congenital malformations as well as for subgroups of major congenital malformations.

Sensitivity analyses-diabetes is a known teratogen ${ }^{33-35}$ and may also be in the causal pathway between obesity and major congenital malformations. In sensitivity analyses, we excluded women with pregestational diabetes to investigate whether the associations between

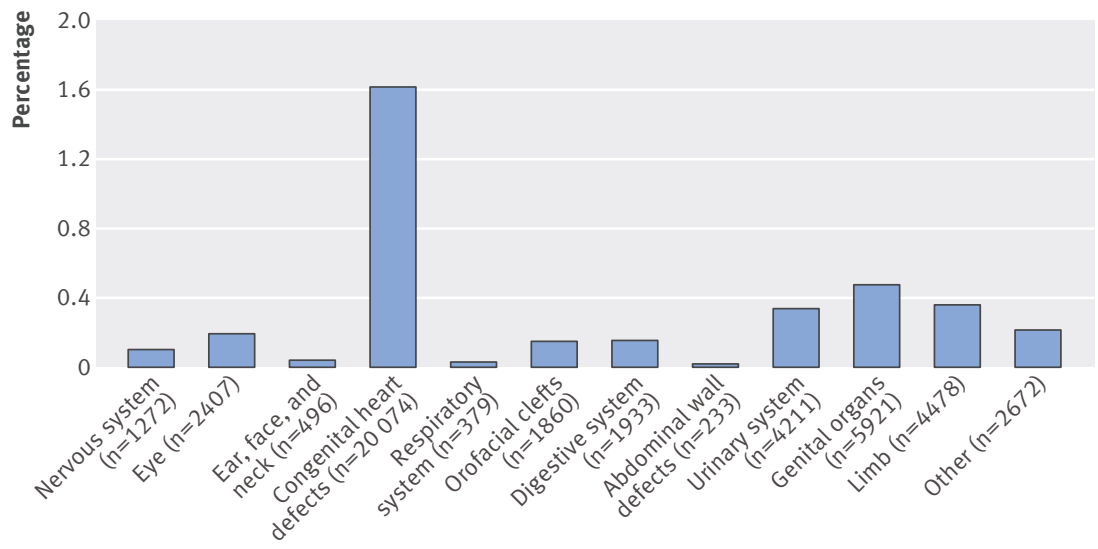

Fig 1 | Prevalence of major congenital malformations in Swedish live singleton births between 2001 and 2014 ( $n=1243957)$
BMI and major congenital malformations were affected. Although gestational diabetes generally develops after the developmentally critical period for malformations, we also performed an analysis where we excluded both women with pregestational diabetes and women with gestational diabetes.

An additional analysis was performed for the association between BMI and the outcome of any chromosomal aberration, genetic syndrome, malformation syndrome with known causes, and viral infection having a possible association with malformations (infants with these conditions were excluded from the study population of the main analyses; $\mathrm{n}=7514$, of whom 6495 had complete data on all variables).

Data were analysed using SAS (version 9.4). We considered two sided $P$ values $<0.05$ to be statistically significant. No adjustment was made for multiple comparisons.

\section{Results}

\section{Major congenital malformations}

During the study period a total of 1243957 liveborn singleton infants were included in the cohort, 43550 (3.5\%) of whom had any major congenital malformation. Congenital heart defects were the most common malformation subtype $(1.6 \%)$ followed by malformations of the genital organs $(0.5 \%)$, limbs $(0.4 \%)$, urinary system $(0.3 \%)$, other $(0.2 \%)$, eye $(0.2 \%)$, digestive system $(0.2 \%)$, orofacial clefts $(0.1 \%)$, and nervous system (0.1\%; fig 1$)$.

\section{BMI and major congenital malformations}

The proportions of offspring with any major congenital malformation were 3.4\% for underweight mothers, 3.4\% for normal weight mothers, 3.5\% for overweight mothers, and 3.8\% for mothers in obesity class I, 4.2\% in obesity class II, and $4.7 \%$ in obesity class III (table 1 ). In unadjusted analyses, risk ratios of any malformation were increased in offspring of overweight mothers, and increased with severity of obesity. A weak U-shaped relation was found between maternal age and risk of any major congenital malformation. Risks of any major congenital malformations were higher in boys than in girls and in offspring of smokers, primiparous women, mothers of low stature, and mothers who were not cohabiting with their partner (table 1). Supplementary eTable 1 provides maternal characteristics by BMI categories.

The adjusted risk ratios of any major congenital malformation increased with maternal overweight and severity of obesity (fig 2). Compared with offspring of normal weight mothers, the adjusted risk ratios for any major congenital malformation increased with maternal BMI: 1.05 (95\% confidence interval 1.02 to 1.07$)$ in overweight mothers, 1.12 (1.08 to 1.15) in mothers in obesity class I, 1.23 (1.17 to 1.30) in mothers in obesity class II, and 1.37 (1.26 to 1.49 ) in mothers in obesity class III (fig 2).

The overall risk of any major congenital malformation was higher in boys (4.1\%) than in girls (2.8\%). In 


\begin{tabular}{|c|c|c|c|c|}
\hline Characteristics & Total No & No (\%) & $\begin{array}{l}\text { Unadjusted risk } \\
\text { ratio }(95 \% \mathrm{Cl})\end{array}$ & Pvalue \\
\hline Total & 1243957 & $43550(3.5)$ & - & \\
\hline \multicolumn{5}{|c|}{ Body mass index $\left(\mathrm{kg} / \mathrm{m}^{2}\right)$ : } \\
\hline$<18.5$ & 29864 & $1020(3.4)$ & 1.00 (0.94 to 1.07$)$ & \multirow{6}{*}{$<.001$} \\
\hline 18.5 to $<25$ & 756432 & $25713(3.4)$ & 1.00 (ref) & \\
\hline 25 to $<30$ & 311339 & $11050(3.5)$ & $1.04(1.02$ to 1.07$)$ & \\
\hline 30 to $<35$ & 103085 & 3903 (3.8) & 1.11 (1.08 to 1.15$)$ & \\
\hline 35 to $<40$ & 31883 & $1335(4.2)$ & $1.23(1.17$ to 1.30$)$ & \\
\hline$\geq 40$ & 11354 & $529(4.7)$ & 1.37 (1.26 to 1.49$)$ & \\
\hline \multicolumn{5}{|l|}{ Maternal age (years): } \\
\hline $13-24$ & 178388 & $6308(3.5)$ & $1.02(0.99$ to 1.05$)$ & \multirow{4}{*}{$<.001$} \\
\hline $25-29$ & 374411 & $12861(3.4)$ & 1.00 (0.97 to 1.02$)$ & \\
\hline $30-34$ & 433659 & $14964(3.5)$ & 1.00 (ref) & \\
\hline$\geq 35$ & 257499 & $9417(3.7)$ & 1.06 (1.03 to 1.09$)$ & \\
\hline \multicolumn{5}{|l|}{ Sex of offspring: } \\
\hline Girl & 604463 & $17107(2.8)$ & 1.00 (ref) & \multirow{2}{*}{$<.001$} \\
\hline Boy & 639494 & $26443(4.1)$ & $1.46(1.43$ to 1.49$)$ & \\
\hline \multicolumn{5}{|l|}{ Maternal height $(\mathrm{cm})$ : } \\
\hline $130-154$ & 41196 & $1556(3.8)$ & 1.10 (1.04 to 1.16$)$ & \multirow{6}{*}{0.006} \\
\hline 155-159 & 126175 & $4544(3.6)$ & 1.05 (1.01to 1.08) & \\
\hline $160-164$ & 318994 & $11181(3.5)$ & $1.02(0.99$ to 1.05$)$ & \\
\hline 165-169 & 362195 & $12457(3.4)$ & 1.00 (ref) & \\
\hline $170-174$ & 272951 & $9523(3.5)$ & $1.01(0.99$ to 1.04$)$ & \\
\hline $175-200$ & 122446 & $4289(3.5)$ & $1.02(0.98$ to 1.05$)$ & \\
\hline \multicolumn{5}{|l|}{ Smoking status: } \\
\hline Non-smoker & 1152475 & $40144(3.5)$ & 1.00 (ref) & \multirow{3}{*}{$<.001$} \\
\hline 1-9 cigarettes/day & 69323 & $2531(3.7)$ & 1.05 (1.01 to 1.09$)$ & \\
\hline$\geq 10$ cigarettes/day & 22159 & $875(3.9)$ & $1.13(1.06$ to 1.21$)$ & \\
\hline \multicolumn{5}{|c|}{ Educational level (years): } \\
\hline$<10$ & 108174 & $4099(3.8)$ & 1.00 (ref) & \multirow{3}{*}{$<.001$} \\
\hline $10-12$ & 478796 & $16854(3.5)$ & 0.93 (0.90 to 0.96$)$ & \\
\hline$>12$ & 656987 & $22597(3.4)$ & 0.91 (0.88 to 0.94$)$ & \\
\hline \multicolumn{5}{|l|}{ Parity: } \\
\hline Primiparous & 553231 & $20076(3.6)$ & 1.07 (1.05 to 1.09$)$ & \multirow{2}{*}{$<.001$} \\
\hline Multiparous & 690726 & $23474(3.4)$ & 1.00 (ref) & \\
\hline \multicolumn{5}{|c|}{ Maternal country of birth: } \\
\hline Nordic* & 985200 & $34552(3.5)$ & 1.00 (ref) & \multirow{2}{*}{0.47} \\
\hline Non-Nordic & 258757 & $8998(3.5)$ & 0.99 (0.97 to 1.01$)$ & \\
\hline \multicolumn{5}{|l|}{ Living with partner: } \\
\hline Yes & 1172665 & $40812(3.5)$ & 1.00 (ref) & \multirow{2}{*}{$<.001$} \\
\hline No & 71292 & $2738(3.8)$ & $1.10(1.06$ to 1.15$)$ & \\
\hline
\end{tabular}

Supplementary eTable 1 provides data for births to mothers with missing data on body mass index. *Sweden, Norway, Denmark, Finland, and Iceland. increasing maternal BMI (P for trend $\leq 0.03$ in all analyses; figs 3 and 4).

The adjusted risk ratios for congenital heart defects by maternal BMI were 1.05 (95\% confidence interval 1.01 to 1.08 ) for overweight mothers, 1.15 (1.09 to 1.20) for mothers in obesity class I, 1.26 (1.16 to 1.37 ) for mothers in obesity class II, and 1.44 (1.27 to 1.63) for mothers in obesity class III. The largest organ specific increases in risk ratios related to overweight and severity of obesity were observed for malformations of the nervous system. Compared with offspring of normal weight mothers, the adjusted risk ratios for malformations in the nervous system were 1.15 (95\% confidence interval 1.00 to 1.31 ) for overweight mothers, 1.44 (1.20 to 1.73) for mothers in obesity class I, 1.65 (1.23 to 2.21) for mothers in obesity class II, and 1.88 (1.20 to 2.94 ) for mothers in obesity class III (fig 3).

When comparing subgroups of malformations in boys and girls, the largest sex difference (with higher proportions for boys) was noted for genital malformations (boys $0.9 \%$ and girls $0.04 \%$ ) and malformations in the urinary system (boys $0.5 \%$ and girls $0.2 \%$; see supplementary eFigure 1). In the sex stratified analyses of malformation subtypes, comparisons were hampered by reduced statistical power in the different BMI categories, especially in girls. The risks of congenital heart defects increased with maternal overweight and severity of obesity for boys, whereas only female offspring of mothers in obesity classes I to III were at increased risks. Maternal BMI was associated with statistically significant increased risks of malformations in the digestive system in boys but not in girls (see supplementary eFigure 2).

Overall, $0.5 \%$ of infants who had diagnoses associated with increased risk of malformations were excluded from the main analyses, with a range from $0.5 \%$ in the offspring of normal weight mothers to $0.8 \%$ in the offspring of mothers in obesity class III. Risks of these malformations also generally increased with maternal overweight and severity of obesity (see supplementary eTable 4).

Sensitivity analysis: exclusion of women with diabetes-after exclusion of women with pregestational and gestational diabetes, the associations between BMI and overall major congenital malformations were materially unchanged (see supplementary eTable 5). malformation in boys of underweight mothers was $4.0 \%$, normal weight mothers was $4.0 \%$, and overweight mothers was $4.3 \%$ and in offspring of mothers in obesity classes I, II, and III was $4.5 \%$, 4.9\%, and $5.3 \%$, respectively (fig 2 ). The corresponding risks in girls were $2.8 \%, 2.8 \%, 2.8 \%, 3.0 \%, 3.4 \%$, and $4.0 \%$. The risk ratios of any malformation increased with maternal severity of obesity in both boys and girls (fig 2).

\section{BMI and specific types of major congenital malformations}

The adjusted risk ratios of malformations of the nervous system, heart, digestive system, genital organs, limbs, and other malformations all increased with

\section{Discussion}

This large population based study found that overall risks of major congenital malformations and risks of several organ specific groups of malformations progressively increase with maternal overweight and severity of obesity. By finding a dose-response relation throughout the spectrum of an above normal body mass index (BMI) and associations between maternal overweight and a range of malformation subgroups, this study substantially expands on previous data, which largely rest on a meta-analysis of pooled studies with varying definitions of obesity and no information on severity of obesity. ${ }^{18}$ 


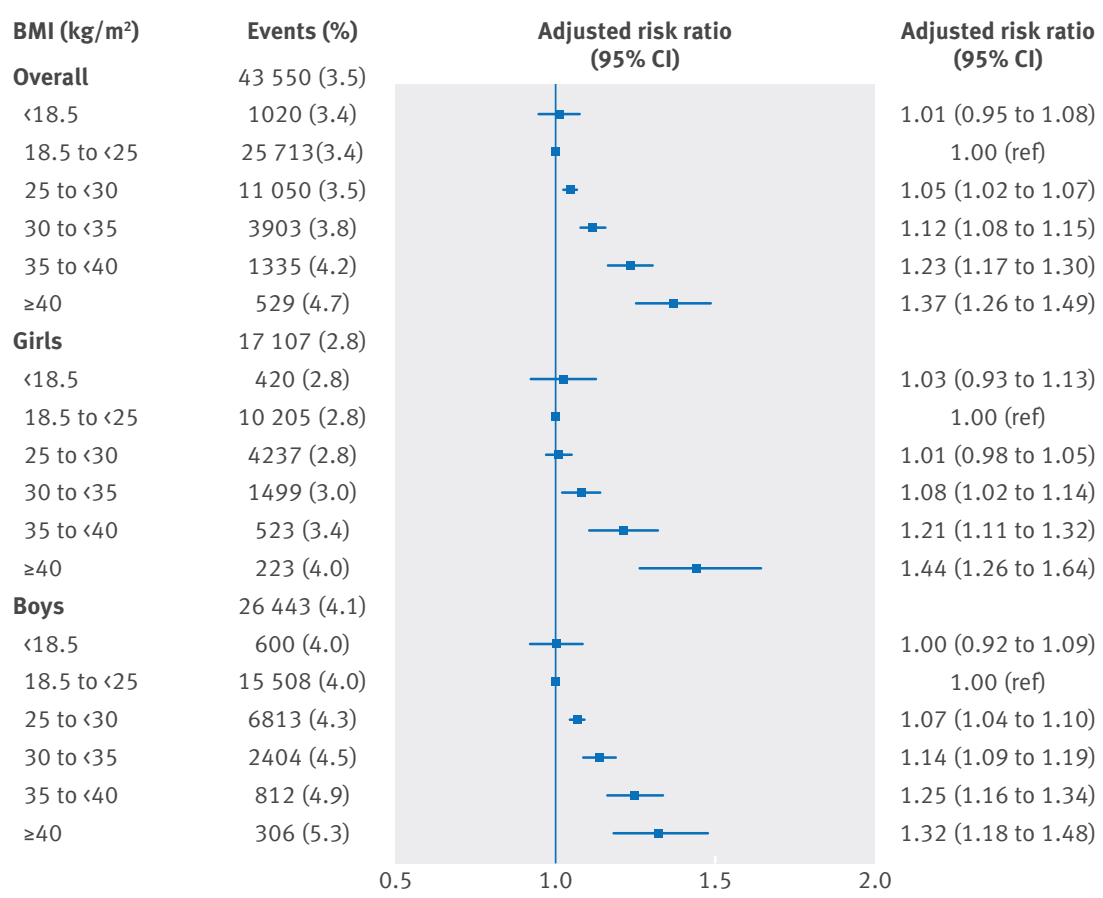

Fig 2 Major congenital malformations in liveborn singletons by maternal body mass index (BMI) in underweight (BMI <18.5; $n=29864$ ), normal weight (BMI 18.5 to $<25 ; n=756432$ ), and overweight (BMI 25 to $<30 ; n=311339$ ) women, and in women in obesity classes I (BMI 30 to $<35 ; n=103085$ ), II (BMI 35 to $<40 ; n=31883)$, and III (BMI $\geq 40 ; n=11354)$. Adjustment was made for maternal age (13-24, 25-29, 30-34, $\geq 35$ years), height (130-154, 155-159, $160-164,165-169,170-174,175-200 \mathrm{~cm}$ ), parity (primiparous, multiparous), early pregnancy smoking status (non-smoker, 1-9, $\geq 10$ cigarettes daily), educational level $(<10$, 10-12, >12 years), maternal country of birth (Nordic (Sweden, Denmark, Finland, Iceland, and Norway), non-Nordic), family situation (living with partner, not living with partner), and sex of offspring singleton births. The large sample size enabled us to investigate the effects of overweight and severity of obesity on risks of major congenital malformations and several specific malformation subgroups. Data on exposures and outcomes were prospectively collected within the universally accessible Swedish healthcare system. Maternal BMI was calculated based on measured weight, which limits recall bias, but height was self reported. We used standard BMI categories as defined by WHO. ${ }^{32}$ Major congenital malformations were classified according to the EUROCAT categorisation. Because we used data from several nationwide registries, we had an opportunity to identify the majority of infants with a diagnosis of a major congenital malformation within the first year of life. Furthermore, we were able to adjust risk estimates for important confounders.

Our study was restricted to live births. Malformations are more common in pregnancies ending in miscarriage or stillbirths, and some prenatally diagnosed malformations may also lead to induced abortions. In particular, most pregnancies complicated by neural tube defects are terminated by induced abortion. ${ }^{7}$ The Swedish national registries with patient level data do not include individual data on malformations in pregnancies with miscarriages, stillbirths, and induced abortions. However, aggregated data for Sweden reported on the EUROCAT website for the period 2007-13 show that there were 551 cases of neural tube defects, of which 396 (72\%) were classified as termination of pregnancy for fetal anomaly. ${ }^{37}$

Antenatal detection of congenital malformations may be more difficult in obese than in normal weight women. ${ }^{38}$ If some malformations in offspring of obese women (notably neural tube defects) were less likely to be diagnosed prenatally and the women underwent an induced abortion, we may have overestimated the risks of malformations in offspring of obese mothers. However, risks may be underestimated if obesity is associated with malformations leading to spontaneous abortion. This hypothesis is supported by findings from studies including information about pregnancy terminations and reporting a doubled risk of neural tube defects and a 50\% increased risk of cardiovascular anomalies in pregnancies with obesity. ${ }^{18}$ In this study we used BMI as a proxy for adiposity. This is a reasonable assumption given the strong correlation between BMI and fat mass in early pregnancy. ${ }^{39}$ We did not have information on the fat distribution, which may be of interest to further explore the association between overweight and severity of obesity and risks of malformations. In addition, we cannot rule out the possibility of residual confounding by unknown or unmeasured factors, such as alcohol use. Power was limited for analyses of less prevalent malformation subgroups by increasing severity of maternal obesity.

\section{Potential mechanisms}

The pathophysiology of malformations is multifactorial, with interactions between genetic and environmental 


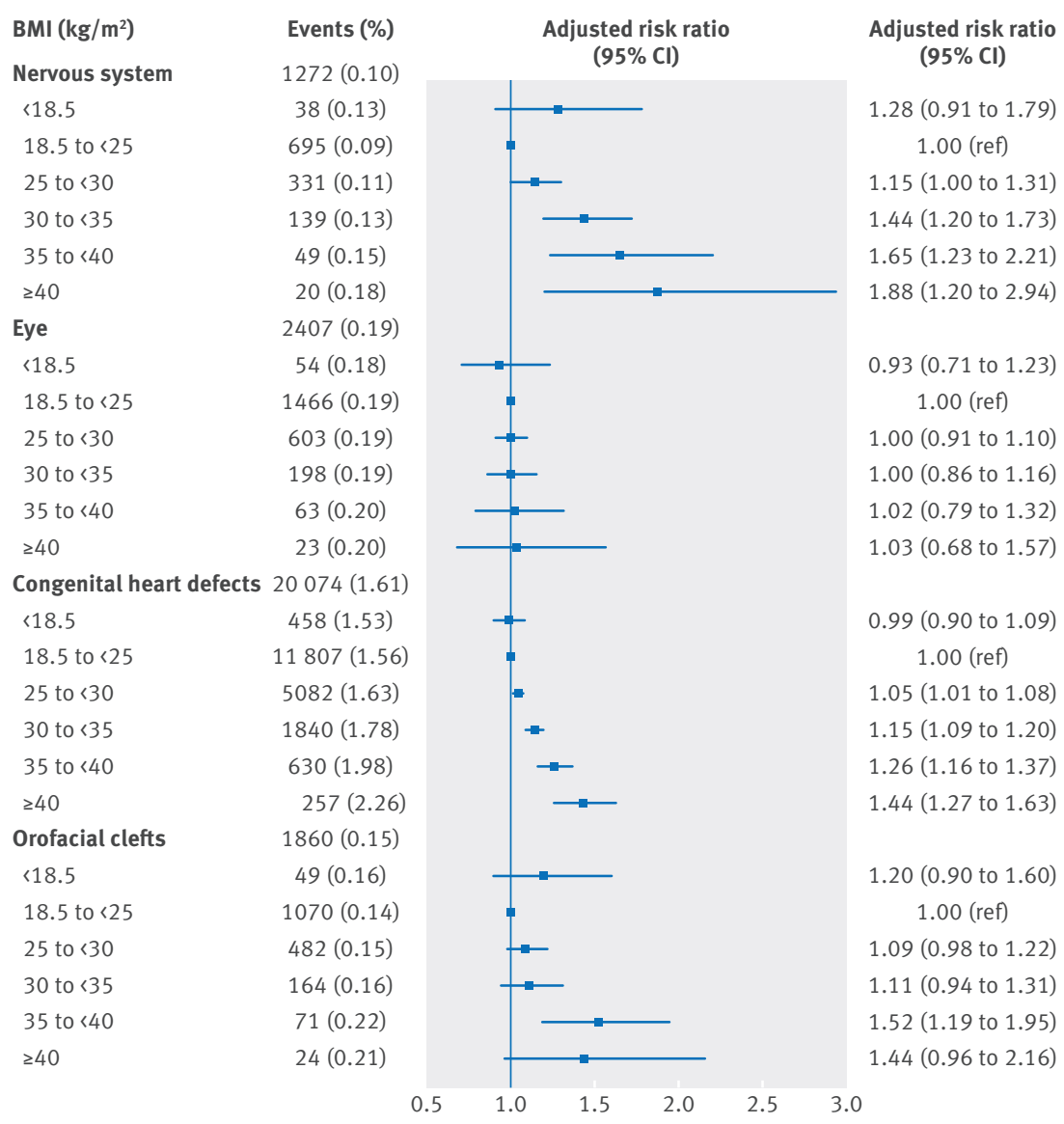

Fig 3 | Major congenital malformations in nervous system, eye, heart, and oral clefts in liveborn singletons by maternal body mass index (BMI) in underweight (BMI <18.5; $\mathrm{n}=29$ 864), normal weight (BMI 18.5 to $<25 ; n=756432$ ), and overweight (BMI 25 to $<30$; $\mathrm{n}=311339$ ) women, and in women in obesity classes I (BMI 30 to $<35 ; n=103085$ ), II (BMI 35 to <40; $n=31883)$, and III (BMI $\geq 40 ; n=11354)$. Adjustment was made for maternal age (13-24, 25-29, 30-34, $\geq 35$ years), height (130-154, 155-159, 160-164, $165-169,170-174,175-200 \mathrm{~cm})$, parity (primiparous, multiparous), early pregnancy smoking status (non-smoker, 1-9, $\geq 10$ cigarettes daily), educational level (<10, 10-12, $>12$ years), maternal country of birth (Nordic (Sweden, Denmark, Finland, Iceland, and Norway), non-Nordic), family situation (living with partner, not living with partner), and sex of offspring risks of malformations are reported to remain increased in obese women after excluding women with diabetes, ${ }^{48}$ and when adjusting for abnormal glucose tolerance in women with glucose values below the threshold of diabetes. ${ }^{49}$ This is in line with our findings of essentially unchanged risks of malformations after exclusion of mothers with diabetes. The possible teratogenic role of other metabolic derangements associated with obesity, such as insulin resistance, hyperlipidemia, and inflammation, is unclear. The adipose tissue is an active metabolic and endocrine organ, ${ }^{50}$ distributed subcutaneously and in the visceral compartment. Visceral obesity in pregnancy is associated with a state of inflammation, vascular dysfunction, and abnormal placental metabolism, ${ }^{51}$ which may adversely influence organogenesis and fetal development.

We found higher risks of several subtypes of malformations in boys than in girls. In particular, risks of genital malformations were markedly higher in boys. One might speculate that this difference may be partly attributed to the clinically more available evaluation of genital structures in boys compared with girls. Data from experimental studies show higher growth rate and substantially higher glucose consumption in males at the embryonal stage, even before sexual differentiation. ${ }^{5253}$ Furthermore, male preimplantation embryos are more vulnerable to heat stress induced production of radical oxygen species than female preimplantation embryos. ${ }^{54}$ One might hypothesize that male embryos are more prone than female embryos to respond with enhanced oxygen radical production to different environmental insults, which in turn could contribute to their increased risk of malformations.

Folic acid supplementation has been associated with decreased risks of neural tube defects and congenital heart malformations. ${ }^{55} 56$ In the present study we did not have information on folic acid supplementation in early pregnancy. However, folic acid deficiency is common in obesity, ${ }^{57}$ and according to a recent national survey from the US, overweight and obese women are less likely to take multivitamins before pregnancy compared with normal weight women. ${ }^{58}$ Thus it is possible that the increased risks of neural tube defects and congenital heart defects in offspring of obese mothers may be partly due to folic acid deficiency.

\section{Conclusion}

We found that risks of major congenital malformations in offspring progressively increase with maternal overweight and severity of obesity. This underlines the importance of having a maternal BMI in the normal range before pregnancy. Preventive effects of weight reduction in early pregnancy cannot be expected as organogenesis occurs within the first eight weeks of gestation. Thus, efforts should be made to encourage women of reproductive age to adopt a healthy lifestyle and to obtain a normal body weight before conception. 


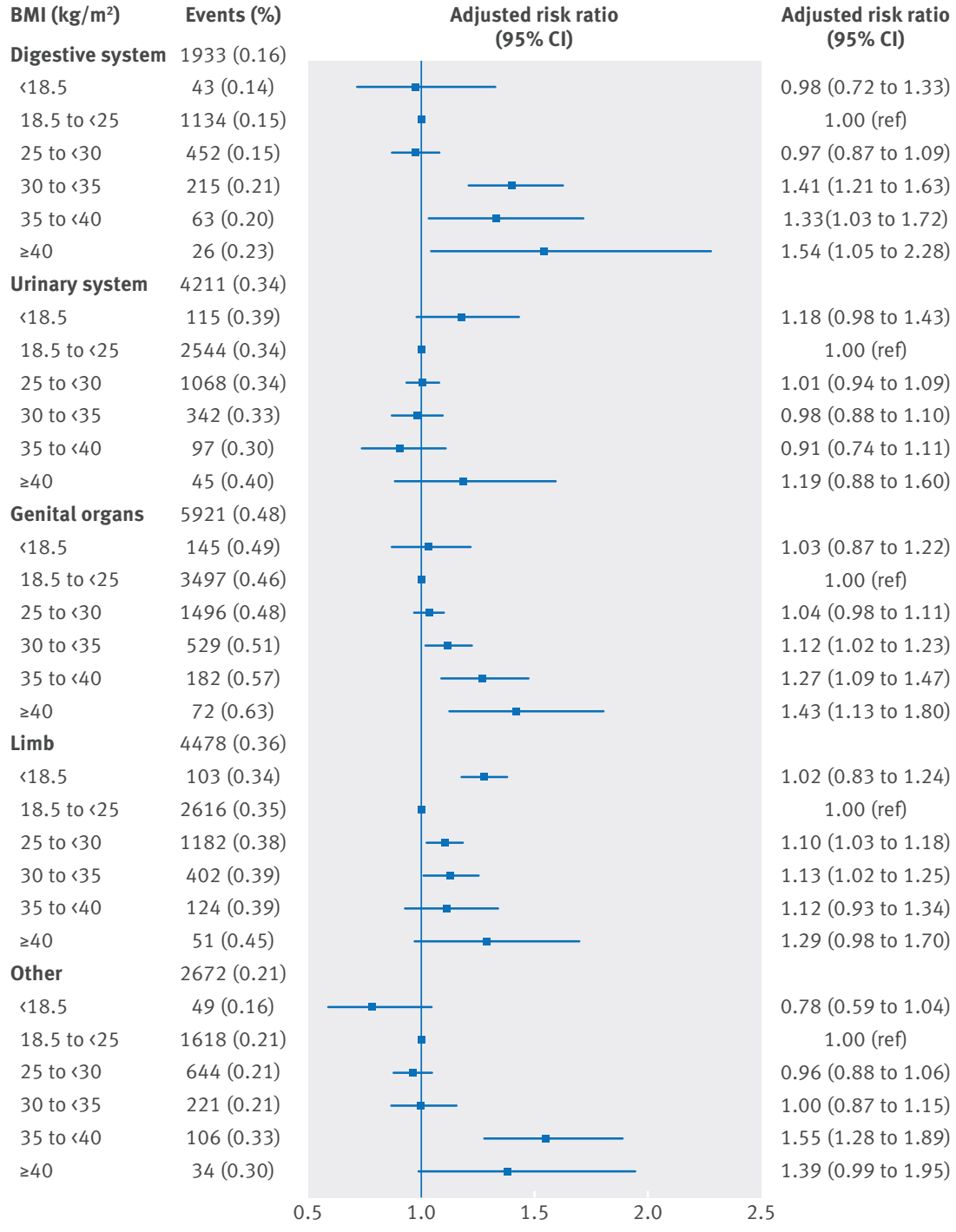

Fig 4 | Major congenital malformations in digestive, urinary, and genital systems; limbs; and other malformations anliveborn singletons by maternal body mass index (BMI) in underweight ( $\mathrm{BMI}<18.5 ; \mathrm{n}=29864$ ), normal weight ( $\mathrm{BMI} 18.5$ to $<25 ; \mathrm{n}=756432$ ), and overweight (BMI 25 to $<30 ; n=311339$ ) women, and in women in obesity classes I (BMI 30 to <35; $n=103085)$, II (BMI 35 to $<40 ; n=31883$ ), and III (BMI $\geq 40 ; n=11354)$. Adjustment was made for maternal age (13-24, 25-29, 30-34, $\geq 35$ years), height (130-154, 155-159, $160-164,165-169,170-174,175-200 \mathrm{~cm}$ ), parity (primiparous, multiparous), early pregnancy smoking status (non-smoker, 1-9, $\geq 10$ cigarettes daily), educational level $(<10$, 10-12, >12 years), maternal country of birth (Nordic (Sweden, Denmark, Finland, Iceland, and Norway), non-Nordic), family situation (living with partner, not living with partner), and sex of offspring study was also funded by the Swedish Research Council for Health, Working Life and Welfare (grant No 2014-0073) and an unrestricted grant from Karolinska Institutet (distinguished professor award to SC). MP was supported by Stockholm County Council (clinical post-doctoral position). OS was supported by the Swedish Research Council (grant No 2013-2429). BP was supported by the Danish Medical Research Council. MN was supported by the Swedish Research Council (grant No 2013-3770) and the National Institutes of Health (award No R01DK105948)

Competing interests: All authors have completed the ICMJE uniform disclosure form at www.icmje.org/coi_disclosure.pdf and declare: no support from any organisation for the submitted work; no financial relationships with any organizations that might have an interest in the submitted work in the previous three years; no other relationships or activities that could appear to have influenced the submitted work. $\mathrm{MN}$ reports being a member of the scientific advisory board for Itrim ( $<\$ 5000$ (£3876; €4430)/year).

Ethical approval: This study was approved by the regional research ethics committee in Stockholm, Sweden (No 2012/1813-31/4).

Data sharing: No additional data available.

Transparency The lead author (MP) affirms that the manuscript is an honest, accurate, and transparent account of the study being reported; that no important aspects of the study have been omitted; and that any discrepancies from the study as planned (and, if relevant, registered) have been explained.

This is an Open Access article distributed in accordance with the Creative Commons Attribution Non Commercial (CC BY-NC 4.0) license, which permits others to distribute, remix, adapt, build upon this work non-commercially, and license their derivative works on different terms, provided the original work is properly cited and the use is non-commercial. See: http://creativecommons.org/licenses/ by-nc/4.0/.

Carmichael SL, Blumenfeld YJ, Mayo J, et al. March of Dimes Prematurity Research Center at Stanford University School of Medicine. Prepregnancy Obesity and Risks of Stillbirth. PLoS One 2015;10:e0138549. doi:10.1371/journal.pone.0138549.

2 Sturm R. Increases in morbid obesity in the USA: 2000-2005. Public Health 2007;121:492-6. doi:10.1016/j.puhe.2007.01.006.

3 Neovius M, Teixeira-Pinto A, Rasmussen F. Shift in the composition of obesity in young adult men in Sweden over a third of a century. Int Obes (Lond) 2008;32:832-6. doi:10.1038/sj.ijo.0803784.

4 Ogden CL, Carroll MD, Lawman HG, et al. Trends in Obesity Prevalence Among Children and Adolescents in the United States, 1988-1994 Through 2013-2014. JAMA 2016;315:2292-9. doi:10.1001/ jama.2016.6361.

5 Branum AM, Kirmeyer SE, Gregory EC. Prepregnancy Body Mass Index by Maternal Characteristics and State: Data From the Birth Certificate, 2014. Natl Vital Stat Rep 2016;65:1-11.

6 Flegal KM, Kruszon-Moran D, Carroll MD, Fryar CD, Ogden CL. Trends in Obesity Among Adults in the United States, 2005 to 2014. JAMA 2016;315:2284-91. doi:10.1001/jama.2016.6458.

7 Welfare NBoHa. Graviditeter,förlossningar och nyfödda. http:// wwwsocilastyrelsense/publikationer 2015.

8 Di Cesare M, Bentham J, et al. NCD Risk Factor Collaboration (NCD-RisC). Trends in adult body-mass index in 200 countries from 1975 to 2014: a pooled analysis of 1698 population-based measurement studies with $19 \bullet 2$ million participants. Lancet 2016:387:1377-96 doi:10.1016/S0140-6736(16)30054-X

9 Cnattingius S, Villamor E. Weight change between successive pregnancies and risks of stillbirth and infant mortality: a nationwide cohort study. Lancet 2016;387:558-65. doi:10.1016/ S0140-6736(15)00990-3.

10 Heslehurst N, Simpson H, Ells LJ, et al. The impact of maternal BMI status on pregnancy outcomes with immediate short-term obstetric resource implications: a meta-analysis. Obes Rev 2008;9:635-83. doi:10.1111/j.1467-789X.2008.00511.x

Contributors: MN and IS had full access to all of the data in the stud and take full responsibility for the integrity of the data and the accuracy of the data analysis. SC, MN, BP, MP, OS, and EV conceived and designed the study. All authors acquired, analysed, and interpreted the data and critically revised the manuscript for important intellectual content. SC, MN, and MP drafted the manuscript. MN and IS carried out the statistical analysis. SC, MN, and OS obtained funding and provided administrative, technical, or material support. MN and JS are the guarantors.

Funding: Research reported in this publication was supported by the National Institute of Diabetes and Digestive and Kidney Diseases of the National Institutes of Health under award number R01DK105948. The content is solely the responsibility of the authors and does not necessarily represent the official views of the National Institutes of Health. The funders were not involved in the design and conduct of the study; collection, management, analysis, or interpretation of the data; and preparation, review, or approval of the manuscript. This

11 Marchi J, Berg M, Dencker A, Olander EK, Begley C. Risks associated with obesity in pregnancy, for the mother and baby: a systematic review of reviews. Obes Rev 2015;16:621-38. doi:10.1111/ obr.12288.

12 Cnattingius S, Villamor E, Johansson S, et al. Maternal obesity and risk of preterm delivery. JAMA 2013;309:2362-70. doi:10.1001/ jama.2013.6295.

13 Persson M, Johansson S, Villamor E, Cnattingius S. Materna overweight and obesity and risks of severe birth-asphyxia-related complications in term infants: a population-based cohort study in Sweden. PLoS Med 2014;11:e1001648. doi:10.1371/journal. pmed.1001648.

14 Johansson S, Villamor E, Altman M, Bonamy AK, Granath F, Cnattingius S. Maternal overweight and obesity in early pregnancy and risk of infant mortality: a population based cohort study in Sweden. BMJ 2014;349:g6572. doi:10.1136/bmj.g6572. 
15 Tennant PW, Rankin J, Bell R. Maternal body mass index and the risk of fetal and infant death: a cohort study from the North of England. Hum Reprod 2011:26:1501-11. doi:10.1093/humrep/der052.

16 Bodnar LM, Parks WT, Perkins K, et al. Maternal prepregnancy obesity and cause-specific stillbirth. Am J Clin Nutr 2015;102:858-64. doi:10.3945/ajcn.115.112250

17 Yoon PW, Olney RS, Khoury MJ, Sappenfield WM, Chavez GF, Taylor D. Contribution of birth defects and genetic diseases to pediatric hospitalizations. A population-based study. Arch Pediatr Adolesc Med 1997:151:1096-103. doi:10.1001/archpedi.1997.02170480026004.

18 Stothard KJ, Tennant PW, Bell R, Rankin J. Maternal overweight and obesity and the risk of congenital anomalies: a systematic review and meta-analysis. JAMA 2009;301:636-50. doi:10.1001/jama.2009.113.

19 Cedergren MI, Selbing AJ, Källén BA. Risk factors for cardiovascular malformation--a study based on prospectively collected data. Scand J Work Environ Health 2002;28:12-7. doi:10.5271/sjweh.641.

20 Cedergren M, Selbing A, Källén B. Geographic variations in possible risk factors for severe cardiac malformations. Acta Paediatr 2002;91:222-8. doi:10.1111/j.1651-2227.2002.tb01699.x.

21 Shaw GM, Nelson V, Moore CA. Prepregnancy body mass index and risk of multiple congenital anomalies. Am J Med Genet 2002;107:253 5. doi:10.1002/ajmg.10164

22 Watkins ML, Botto LD. Maternal prepregnancy weight and congenital heart defects in offspring. Epidemiology 2001;12:439-46. doi:10.1097/00001648-200107000-00014.

23 Cedergren MI, Källén BA. Maternal obesity and infant heart defects. Obes Res 2003;11:1065-71. doi:10.1038/oby.2003.146.

24 Shaw GM, Quach T, Nelson V, et al. Neural tube defects associated with maternal periconceptional dietary intake of simple sugars and glycemic index. Am J Clin Nutr 2003;78:972-8.

25 Socialstyrelsen. Socialstyrelsen 2003 http://www.socialstyrelsen.se/ Lists/Artikelkatalog/Attachments/10655/2003-112-3_20031123.pdf.

26 Ludvigsson JF, Otterblad-Olausson P, Pettersson BU, Ekbom A. The Swedish personal identity number: possibilities and pitfalls in healthcare and medical research. Eur J Epidemiol 2009;24:659-67. doi:10.1007/s10654-009-9350-y.

27 Ludvigsson JF, Andersson E, Ekbom A, et al. External review and validation of the Swedish national inpatient register. BMC Public Health 2011;11:450. doi:10.1186/1471-2458-11-450.

28 Ludvigsson JF, Almqvist C, Bonamy AK, et al. Registers of the Swedish total population and their use in medical research. Eur J Epidemiol 2016;31:125-36. doi:10.1007/s10654-016-0117-y.

29 Glinianaia SV, Rankin J, Wright C. Congenital anomalies in twins: a register-based study. Hum Reprod 2008;23:1306-11. doi:10.1093/ humrep/den104.

30 Pasternak B, Svanström H, Mølgaard-Nielsen D, Melbye M, Hviid A Metoclopramide in pregnancy and risk of major congenital malformations and fetal death. JAMA 2013;310:1601-11. doi:10.1001/ jama.2013.278343.

31 Villamor E, Bosch RJ. Optimal treatment of replicate measurements in anthropometric studies. Ann Hum Biol 2015;42:507-10. doi:10.3109/03014460.2014.969488.

32 WHO. Global Database on Body Mass Index. http://appswhoint/bmi/ index 2015

33 Kitzmiller JL, Buchanan TA, Kjos S, Combs CA, Ratner RE. Preconception care of diabetes, congenital malformations, and spontaneous abortions. Diabetes Care 1996;19:514-41.

34 Hanson U, Persson B, Thunell S. Relationship between haemoglobin A1C in early type 1 (insulin-dependent) diabetic pregnancy and the occurrence of spontaneous abortion and fetal malformation in Sweden. Diabetologia 1990;33:100-4

35 Suhonen L, Hiilesmaa V, Teramo K. Glycaemic control during early pregnancy and fetal malformations in women with type I diabetes mellitus. Diabetologia 2000;43:79-82

36 Cai GJ, Sun XX. Zhang L, Hong Q. Association between maternal body mass index and congenital heart defects in offspring: a systematic review. Am J Obstet Gynecol 2014;211:91-117. doi:10.1016/j. ajog.2014.03.028.

37 EUROCAT. European Surveillance of Congenital Anomalies 2017. http://www.eurocat-network.eu/.

38 Dashe JS, McIntire DD, Twickler DM. Maternal obesity limits the ultrasound evaluation of fetal anatomy. / Ultrasound Med 2009;28:1025-30. doi:10.7863/jum.2009.28.8.1025.

39 Sewell MF, Huston-Presley L, Amini SB, Catalano PM. Body mass index: a true indicator of body fat in obese gravidas. / Reprod Med 2007:52:907-11.
40 Tomson T, Battino D, Bonizzoni E, et al. EURAP study group. Dose-dependent risk of malformations with antiepileptic drugs: an analysis of data from the EURAP epilepsy and pregnancy registry. Lancet Neurol 2011;10:609-17. doi:10.1016/S1474-4422(11) 70107-7.

41 Leite M, Albieri V, Kjaer SK, Jensen A. Maternal smoking in pregnancy and risk for congenital malformations: results of a Danish register-based cohort study. Acta Obstet Gynecol Scand 2014;93:825 34. doi:10.1111/aogs.12433.

42 Hackshaw A, Rodeck C, Boniface S. Maternal smoking in pregnancy and birth defects: a systematic review based on 173687 malformed cases and 11.7 million controls. Hum Reprod Update 2011;17:589604. doi:10.1093/humupd/dmr022.

43 Sokol RJ, Delaney-Black V, Nordstrom B. Fetal alcohol spectrum disorder. JAMA 2003;290:2996-9. doi:10.1001/jama.290.22.2996.

44 Catalano P, deMouzon SH. Maternal obesity and metabolic risk to the offspring: why lifestyle interventions may have not achieved the desired outcomes. Int J Obes (Lond) 2015;39:642-9. doi:10.1038/ ijo.2015.15.

45 Persson M Norman M. Hanson U. Obstetric and perinatal outcomes in type 1 diabetic pregnancies: A large, population-based study. Diabetes Care 2009;32:2005-9. doi:10.2337/dc09-0656.

46 Hanson U, Persson B, Thunell S. Relationship between haemoglobin $\mathrm{A} 1 \mathrm{C}$ in early type 1 (insulin-dependent) diabetic pregnancy and the occurrence of spontaneous abortion and fetal malformation in Sweden. Diabetologia 1990;33:100-4. doi:10.1007/BF00401047.

47 Eriksson UJ, Borg LA. Diabetes and embryonic malformations. Role of substrate-induced free-oxygen radical production for dysmorphogenesis in cultured rat embryos. Diabetes 1993;42:411-9. doi:10.2337/diab.42.3.411

48 Waller DK, Shaw GM, Rasmussen SA, et al. National Birth Defects Prevention Study. Prepregnancy obesity as a risk factor for structural birth defects. Arch Pediatr Adolesc Med 2007;161:745-50. doi:10.1001/archpedi.161.8.745.

49 Brite J, Laughon SK, Troendle J, Mills J. Maternal overweight and obesity and risk of congenital heart defects in offspring. Int J Obes (Lond) 2014:38:878-82. doi:10.1038/ijo.2013.244.

50 Scherer PE. The Multifaceted Roles of Adipose Tissue-Therapeutic Targets for Diabetes and Beyond: The 2015 Banting Lecture. Diabetes 2016;65:1452-61. doi:10.2337/db16-0339.

51 Jarvie E, Hauguel-de-Mouzon S, Nelson SM, Sattar N, Catalano PM, Freeman DJ. Lipotoxicity in obese pregnancy and its potential role in adverse pregnancy outcome and obesity in the offspring. Clin Sci (Lond) 2010;119:123-9. doi:10.1042/cs20090640.

52 Gutiérrez-Adán A, Perez-Crespo M, Fernandez-Gonzalez R, et al. Developmental consequences of sexual dimorphism during pre-implantation embryonic development. Reprod Domest Anim 2006:41(Suppl 2):54-62. doi:10.1111/j.1439-0531.2006.00769.x.

53 Tiffin GJ, Rieger D, Betteridge KJ, Yadav BR, King WA. Glucose and glutamine metabolism in pre-attachment cattle embryos in relation to sex and stage of development. / Reprod Fertil 1991;93:125-32. doi:10.1530/jrf.0.0930125.

54 Pérez-Crespo M, Ramírez MA, Fernández-González R, et al. Differential sensitivity of male and female mouse embryos to oxidative induced heat-stress is mediated by glucose-6-phosphate dehydrogenase gene expression. Mol Reprod Dev 2005;72:502-10. doi:10.1002/ mrd.20366.

55 De-Regil LM, Peña-Rosas JP, Fernández-Gaxiola AC, Rayco-Solon P. Effects and safety of periconceptional oral folate supplementation for preventing birth defects. Cochrane Database Syst Rev 2015;14:CD007950.

56 Feng Y, Wang S, Chen R, Tong X, Wu Z, Mo X. Maternal folic acid supplementation and the risk of congenital heart defects in offspring: a meta-analysis of epidemiological observational studies. Sci Rep 2015:5:8506. doi:10.1038/srep08506.

57 Thomas-Valdés S, Tostes MDGV, Anunciação PC, da Silva BP, Sant’Ana HMP. Association between vitamin deficiency and metabolic disorders related to obesity. Crit Rev Food Sci Nutr 2017;57:3332-43.

58 Masho SW, Bassyouni A, Cha S. Pre-pregnancy obesity and non-adherence to multivitamin use: findings from the National Pregnancy Risk Assessment Monitoring System (2009-2011). BMC Pregnancy Childbirth 2016;16:210.

Supplementary web appendix: eTables 1-5 and eFigures 1 and 2 